\title{
COVID 19 Y LOS DESAFÍOS EDUCATIVOS DEL PRESENTE
}

\section{COVID 19 AND THE EDUCATIONAL CHALLENGES OF THE PRESENT}

\author{
Mario Sobarzo Morales \\ Doctor en Filosofía Moral y Política \\ Académico Universidad de Santiago de Chile \\ mario.sobarzo.m@usach.cl
}

\begin{abstract}
Resumen: En el presente texto se abordan dos aspectos relevantes para interpretar el modo en que se desarrollará el sistema educativo y cómo se puede adaptar a las transformaciones que el covid 19 está produciendo en nuestro planeta. En primer lugar, se interpretará el contexto macro, es decir, se hará una lectura de las implicancias económicas, pues son centrales en los objetivos de cualquier sistema educativo; pero, también de las políticas, en la medida que en los modernos Estados Nacionales, esta es una dimensión constitutiva de los educativo en sus aspectos formales tanto como informales; también se considerarán las implicancias sociales y culturales involucradas. En segundo lugar, se intentará pensar la importancia de los intempestivo, lo emergente, como oportunidad de desarrollo para una educación vinculada con las necesidades de las comunidades tanto a nivel global, nacional, como territorial, entendiendo por esto último lo que marca físicamente el espacio de interacción cotidiana.
\end{abstract}

Palabras Clave: Educación en cuarentena, Apagón educativo global, 4ª revolución industrial, Formación social, Sociedad del riesgo mundializada

Abstract: This text addresses two relevant aspects, to interpret how the educational system will develop and how it can adapt to the transformations that COVID 19 is producing on our planet. Firstly, the macro context will be interpreted, that is to say, a reading will be made of the economic implications since they are central to the objectives of any educational system; but also of the policies, to the extent that they are a constitutive dimension of education in both its formal and informal aspects in modern Nation-States. The social and cultural implications involved will also be considered. Secondly, an attempt will be made to think about the importance of the untimely, the emerging, as an opportunity for development for an education linked to the needs of the communities both at a global and national level, as well as at a territorial level, understanding by this last point what physically marks the space of daily interaction.

Key Words: Quarantined education, Global education blackout, $4^{\text {th }}$ industrial revolution, Social formation, Global risk society 
Cerca del Líder hay una ventana donde juego al cine ya no corren niños ni hay negocios de barrio por este lugar. Y todas las casas tienen rejas, como no, la televisión cierra la puerta más encima que te quieren encerrar pa cobrar, pa comprar, encerrar, encerrar...

Es de día. La Floripondio

\section{0: EL AÑO DEL RIESGO MULTIDIMENSIONAL}

El año 2020 será recordado como un momento central de las continuas evoluciones a las que el capitalismo, con todas sus implicancias sociales, políticas, culturales, etc., nos ha sometido en los últimos tres siglos. La pandemia del covid 19 reconfiguró aspectos centrales del vivir humano, no tanto por sí misma, como por los aspectos involucrados que necesitaron adaptarse para conservar cierto nivel de operatividad que evitaran el parón productivo a nivel global. Por primera vez el moderno sistema de Estados - Nación coordinó y aplicó medidas como cuarentenas nacionales en gran cantidad de países, restricciones a las libertades, intervención en la vida cotidiana de las personas y, en la actualidad, se aprestan a realizar procesos de vacunación de carácter global. En este contexto, la educación ha sido uno de los lugares más afectados, pero también donde se han producido reflexiones, análisis, discusiones, en torno a los objetivos y principios que deberán orientar su desarrollo en el corto, mediano y largo plazo. De este modo, en el presente texto se abordan dos aspectos relevantes para interpretar el modo en que se desarrollará el sistema educativo y cómo se puede adaptar a las transformaciones que el covid 19 está produciendo en nuestro planeta. En primer lugar, se interpretará el contexto macro, es decir, se hará una lectura de las implicancias económicas, pues son centrales en los objetivos de cualquier sistema educativo; pero, también de las políticas, en la medida que en los modernos Estados Nacionales, esta es una dimensión constitutiva de los educativo en sus aspectos formales tanto como informales; también se considerarán las implicancias sociales y culturales involucradas. En segundo lugar, se intentará pensar la importancia de los intempestivo, lo emergente, como oportunidad de desarrollo para una educación vinculada con las necesidades de las comunidades tanto a nivel global, nacional, como territorial, entendiendo por esto último lo que marca físicamente el espacio de interacción cotidiana.

\section{UNA PANDEMIA ECONÓMICA}

El sociólogo alemán Ulrich Beck publicó en 1986 el libro La Sociedad del Riesgo Global (Beck, La sociedad del riesgo global, 2002). En dicho texto la tesis central es que el desarrollo inherente a las formas productivas y científicas impide anticipar las constantes crisis a las que nos someten sus cambios. La más ínfima partícula o el experimento más inocuo pueden tener alcances devastadores. En un mundo donde ciencia y tecnología están inventando y desarrollando constantemente innovaciones, es imposible anticipar los riesgos que esto 
puede tener. Ni el máximo nivel de seguridad es infalible y, por el contrario, los riesgos son exponenciales al manejo de la vida, la naturaleza y las energías. Además, estos riesgos se vuelven constantes con las que se convive y que por lo mismo se normalizan, tornándose crónicos. A pesar de la sorpresa que representó la aparición de un virus para el que no se tenía medicamentos ni vacunas adecuados, la respuesta generalizada de las poblaciones a nivel global estuvo lejos de las imágenes a las que Hollywood nos tiene acostumbrados en sus películas de catástrofe. Por el contrario, millones de personas estuvieron en condiciones de obedecer las instrucciones de sus gobiernos, aceptar las cuarentenas, entre otras medidas que funcionaron en un margen de relativa normalidad. Convivimos con el riesgo y hemos aprendido a funcionar en sus márgenes.

El año 2007 (Beck, La sociedad del riesgo mundial. En busca de la seguridad perdida, 2008) volvió sobre sus tesis de 20 años antes, pero en el marco de las transformaciones producidas por la caída del bloque socialista y el triunfo del neoliberalismo, que alcanzó carácter mundial. En un momento donde las políticas neoliberales llegaron a permitir que se lucrara con fondos públicos dirigidos a educación en países como Suecia, punta de lanza de las políticas de bienestar implementadas en Europa después de la Segunda Guerra Mundial. El autor se percató que, aunque los riesgos son mundiales, el modo de valorar su peligro potencial está localizado según la zona geográfica y político-económica en que se encuentran las personas. Debido a que la ideología neoliberal antepone los negocios a las políticas mundiales que serían necesarias para afrontar crisis como el cambio climático, la contaminación, la deforestación, la crisis del agua, etc., los peligros, los daños, en fin, todo lo que tiene que ver con la subsistencia, no afectan de igual modo a quienes poseen poder económico que a quienes son los más desvalidos socialmente. En Chile sabemos bastante bien de esto, pues las zonas de sacrificio son en lugares populares y siempre tienen al frente a mega empresarios dueños de una influencia que trasciende lo económico. Por esto, Ulrich Beck, se percató que resultaba muy difícil convencer a los países desarrollados, que no vivían los daños de modo directo, de adoptar medidas para paliar la crisis climática, el problema del agua potable, la contaminación, la deforestación del Amazonas, entre muchas otras. Las sociedades ricas y las sociedades pobres, al igual que las clases acomodadas versus las clases menesterosas en nuestras sociedades latinoamericanas y tercermundistas, tenemos culturas del riesgo distintas que, unidas a nuestra ignorancia sobre las consecuencias que puedan suceder (inherente a su novedad), amplifican el peligro y su impacto. En el caso de nuestro país hemos podido vivir de modo flagrante ${ }^{1}$ lo que esta diferente valoración del riesgo significa.

Aunque existen bastantes posibilidades de que la crisis sanitaria producida por el covid 19 se termine, o al menos se reduzca gracias a las vacunas, lo cierto es que los riesgos seguirán en aumento. La pandemia no vino a cambiar el mundo como lo conocíamos, pues los comportamientos, las políticas, la reducción de libertades en pos de afrontar catástrofes, etc., han existido desde hace mucho tiempo, pero como lo señala Beck, el neoliberalismo ha diferenciado los potenciales de riesgo y elitizado las formas de reacción estatal y privada. En el caso de Chile el reporte anual sobre el aumento de fallecimientos fue extremadamente

\footnotetext{
${ }^{1}$ Incluso la esposa del presidente se va de vacaciones con sus 2 hijas a Miami, luego regresa al país y no realiza los 10 días de cuarentena que dicta el protocolo. A 4 días de su llegada aparece en una rueda de prensa acompañando a su marido, Sebastián Piñera (Sepúlveda, 2020).
} 
brutal en su manifestación: la mayoría de las comunas que superaron el 30\% de mortalidad respecto de los años anteriores, son comunas populares. El dato es consistente con toda la información que nos indica que la desigualdad es el orden articulante y el mayor punto de contradicciones para nuestro sistema político y social. Los graves resultados de la táctica del "sálvate solo" que se volvió dominante a nivel mundial ha llevado a algunos autores a señalar que gracias a la crisis sanitaria mundial advendría el comunismo².

Hoy podemos afirmar con más seguridad que el COVID-19 más que cambiar algo, ha sido el justificativo y el acelerante de cambios que ya venían ocurriendo. En este caso, estamos hablando de transformaciones en las formas de producción de riqueza. Esto es fundamentalmente un cambio económico, pero no sólo eso. La economía no es un trascendental, algo inalterable y cuya comprensión sea invariante en el tiempo, sino más bien, lo contrario. En la medida que se encuentra en lo social, en la sociedad, sus contradicciones se viven en ella. En el límite entre esas contradicciones y el modo en que un sistema como el neoliberal las procesa, un lugar central se encuentra en el sistema escolar, la escuela y la institución docente.

Como lo señala Marx en textos como La Ideología Alemana (Marx K. y., 1974) o los Manuscritos de 1844 al hablar de la enajenación (Marx K. , 1970), el proceso de naturalización del orden económico implica una borradura amplia que aborda temas tan variados como los valores axiales de las sociedades, la configuración de la estructura productiva y hasta la propia subjetividad. Tres aspectos que son centrales en el sistema educativo desde los orígenes de la educación moderna, donde la exaltación patria iba unida al aprendizaje del oficio y una serie de comportamientos inherentes a él.

En ese sentido, cabe señalar que la pandemia ha dejado en evidencia la profunda transformación económica que estamos viviendo, lo que implica que las categorías económicas con que se piensa la transformación actual están tan desajustadas para interpretar el cambio, como las educativas, las sociales, las políticas, etc. Hasta aquí no conseguimos identificar suficientemente los contornos de lo que está sucediendo, sin embargo, existen interpretaciones que resultan muy relevantes a la hora de pensar este vínculo entre lo económico, lo subjetivo y la técnica - tecnología, que inciden directamente en la escuela y el proceso educativo.

El investigador venezolano en temas educativos Luis Bonilla - Molina (Bonilla - Molina, 2020), al inicio de la pandemia en el sur del mundo escribió un texto señalando que la pandemia venía a servir para una reingeniería social global que de otro modo habría sido imposible por la envergadura de seres humanos que era necesario intervenir para adaptar al nuevo cambio económico que él identificó con la cuarta revolución industrial.

Para el Foro Económico Mundial (WEF) la 4⿳亠丷a revolución industrial está en proceso (Perasso, 2016) e implica una unión de diversas tecnologías que transformarán de modo radical el mundo del trabajo y la producción. Su avance se sustenta sobre las transformaciones de la 3a Revolución, que se basó el desarrollo de tecnologías digitales, comunicacionales y de transporte. En la $4^{a}$, la ciencia y la tecnología permitirán la integración

\footnotetext{
2 Para más referencias véase el libro Pandemia de Slavoj Zizek que sintetiza y desarrolla sus tesis expuestas en
} textos periodísticos (Zizek, 2020). 
del cerebro y la máquina, el desarrollo de sistemas autónomos integrados con capacidad de decisión y transformaciones genéticas.

En este contexto de crisis, la pandemia mundial fue el momento para acelerar las transformaciones en un mundo donde la tercera revolución aún tiene niveles de desigualdad aberrantes. Si la 3 a revolución implicó una brecha que hasta el día de hoy sigue aumentando (países integrados vs países atrasados y poblaciones globalizadas vs poblaciones rezagadas), la 4 a puede tener un impacto catastrófico en términos laborales y educativos.

En el caso de esta nueva revolución, aunque su avance ha sido sistemático desde que las tecnologías han adquirido mayor grado de independencia a la gestión humana (al punto que la internet de las cosas y las impresoras 3D ya son una realidad), con la actual pandemia se aceleró, lo que ha tenido impacto en áreas significativas.

Este impacto tiene connotaciones que aún no se logran identificar, por ejemplo, en $e l$ Informe sobre la estabilidad financiera mundial (GFSR) del FMI, el año 2012 (FMI, 2012) se señala a los ancianos como una virtual amenaza para el desarrollo de los países por su alto costo social e incentiva a los Estados a preparar mecanismos para adaptarse al nuevo contexto de riesgo de longevidad. En un escenario de automatización, ¿qué sucederá con esta población excedente?

Desde que se formulara la teoría del capital humano de Schultz y Becker los procesos de transformación de la relación capital - trabajo han tenido un desarrollo acelerado dando origen según el obrerismo italiano (Negri, Lazzrato, Tronti, Virno, entre otros) a un capitalismo cognitivo que ya no tiene como ejes la serialidad, masividad y repetición, sino la unicidad, la exclusividad y la creatividad humanas. El proceso de virtualización está directamente conectado con la virtuosidad dirá Paolo Virno en Primero de mayo (la ciudad fábrica) (Expósito, 2004), documental de Marcelo Expósito33, lo que conlleva un cambio en el paradigma productivo y la transformación de los principales rasgos de la acumulación capitalista. No es acumulación de productos tangibles, sino de plataformas, trabajo en red, innovaciones tecnológicas, etc., que requieren nuevas habilidades, conocimientos y capacidades. Este rasgo no resulta menor considerando que a lo largo de la historia, todas las transformaciones productivas han llevado anejos cambios en las formaciones sociales. Esto implica que no sólo cambia el modo en que se produce, sino también las subjetividades, la educación, las instituciones sociales y políticas, etc. ${ }^{4}$

La transformación del esclavismo al feudalismo cambió estructuras mentales tan profundas como el paso de la intramundanidad a la extramundanidad (gloria e inmortalización en la Tierra a salvación en el más allá) como búsqueda de la vida; nuevas formas religiosas y morales (religión pagana a monoteísmo católico y moral cívica a una privada); una reconfiguración de las formas de habitar (Civitas antigua a feudos medievales) y de las propias estructuras sociales (de un sistema clientelar con otros ciudadanos y los

\footnotetext{
${ }^{3}$ Visible en: https://www.hamacaonline.net/titles/primero-de-mayo-la-ciudad-fabrica/

${ }^{4}$ Por supuesto, un análisis pormenorizado de lo que se expondrá necesitaría un desarrollo en sí mismo. Esto sólo intenta ser una síntesis bastante simplificada de fenómenos tremendamente complejos y que ocurren en un largo plazo.
} 
esclavos como propiedad, a servidumbre) que no eran adecuadas en contextos de fragmentación territorial.

El paso de la forma feudal a la forma capitalista implicó el nacimiento del sujeto como base del conocimiento (filosofía); del liberalismo y la idea de libertad individual como forma de la política (de ahí el olvido del azar como principio de una democracia directa y el privilegio por el voto y la democracia representativa); del reemplazo de la religión como principio de certidumbre y el gran desarrollo de la ciencia; de la educación regimentalizada moderna con sus currículum prescriptivos; incluso, a nivel literario, implicó el nacimiento de la novela moderna (donde El Quijote es un hito como construcción de personajes y situaciones cotidianas); o el desarrollo del amor romántico, en muchos puntos conectado con el fetichismo de la mercancía. Los cambios abarcan todos los ámbitos sociales.

El concepto de formación social de Marx significa ${ }^{5}$ la articulación de un grupo humano basado en lo económico, lo jurídico - institucional y la ideología que es dominante en ese sistema (Revista Internacional Marx Ahora, 2014).

Estas formaciones son históricas y cambian a medida que aparecen nuevas formas de producción que obligan a una reconfiguración de toda la sociedad para adecuarse a lo nuevo. En el caso del capitalismo, tanto la esclavitud como el modelo de servidumbre feudal son inadecuados para incorporarse a él, pues disuelven su principio ideológico fundamental: el contrato libre y en condiciones de igualdad entre el productor y el dueño del capital. Como este principio es verdadero jurídicamente, pero falso materialmente, se empiezan a generar cada vez más contradicciones.

Para entender el verdadero alcance de los cambios que lleva dentro un nuevo sistema productivo y su formación social, debemos entender el fundamento de las contradicciones del anterior, que son las que quedan superadas en el emergente.

En el esclavismo el principio de contradicción es que se le pide a una cosa (una propiedad) que sea el ente productor. No hay riqueza en el sentido de capital, sino de poder social y gloria. La forma que adquiere la exclusión es política y social, no económica ni jurídica, pues en tanto propiedad el esclavo está regulado por el sistema legal (ejemplo romano). Sin embargo, en términos económicos esto resulta insostenible, pues necesita aumentar cada vez más la población esclava y para hacerla productiva está obligado a un uso constante de la fuerza. Aunque todos los sistemas esclavistas tienen mecanismos de manumisión, en general la esclavitud es vista como una muerte cívica y política (Patterson, 1991). El cristianismo permitió resolver esta contradicción dotando a todos/as de alma, los hizo personas, aunque siguieran excluidos políticamente. Al dotar a esos meros entes parlantes de alma y convertirlos en personas, los integró como sujetos jurídicos, gracias a lo cual podían hacer contratos de servidumbre. La reubicación jurídica era necesaria para el funcionamiento de la nueva forma productiva.

En el feudalismo el principio de contradicción es que dos personas hacen un pacto ante Dios que une protección y cuidado con disposición física total (sexual, militar, laboral). Esto tiene sentido si (y sólo sí) la comunidad y el territorio es pequeño, pues se sustenta en

\footnotetext{
${ }^{5}$ En términos bastante poco sutiles y respetuosos de la larga historia problemática que el artículo de la
} Revista Marx Ahora explica. 
la autarquía. Un rasgo básico de la producción (y su aumento) es su intercambio, su circulación, desde las más rudimentarias formas, como el trueque. Eso lo limita el sistema de producción feudal, cerrado sobre sí mismo e incapaz de asumir un crecimiento desmedido de la mano de obra. En esta forma de producción tampoco existe riqueza, sino sólo la tierra y la cantidad de almas que es capaz de sustentar. La contradicción es inherente al sistema: baja productividad, hambrunas, expoliación a tal nivel que conllevaba rebeliones, huidas, así como luchas constantes y rapiña entre los distintos señores, etc.

A diferencia de los dos modelos anteriores el capital funciona mediante una compleja mediación de múltiples formas entre la producción social y la apropiación privada. El capital no es otra cosa que una gran acumulación de trabajo muerto que le permite al capitalista comprar más fuerza de trabajo para generar nueva riqueza. La propiedad sobre la mina, la tierra, el agua, entre otros recursos, queda encubierta por estas mediaciones de tipo legal, cultural, social, que la vuelven aceptable.

Bourdieu y Passeron (Bourdieu, 1977) estudiaron la profunda vinculación que existe entre el sistema de clases sociales (propia del capitalismo) y el sistema educativo francés. Mecanismos como la selección o las pruebas estandarizadas evidencian esta segmentación de clase que discurre invisible bajo la forma del habitus, permitiendo su normalización social. Sin el mito de la meritocracia una mayor cantidad de jóvenes se saldría del sistema mucho antes de ingresar al proceso de selección universitaria.

En Latinoamérica las contradicciones en el ámbito del conocimiento y la educación, son radicales: marcan un proceso de imperialismo técnico - tecnológico (el caso de la fabricación de las vacunas contra el covid 19 es un ejemplo), pero también, transformaciones respecto al rol de la vida humana y las desigualdades sociales que estamos dispuestos a tolerar. Esto es lo que la pandemia vino a dejar en evidencia de modo tan flagrante en Chile. Mientras las seis grandes fortunas del país incrementaron su capital durante el año 2020, según la Revista Forbes, más de 3 millones de cotizantes quedaron sin dinero en sus cuentas de pensiones individuales. A medida que las escuelas y colegios se acercan territorial o simbólicamente (colegios particulares de otras comunas o ciudades) a la educación de las tres comunas más ricas de Chile, es mayor el éxito en las pruebas estandarizadas, el ingreso a la universidad y el acceso a los puestos más rentables económicamente. Este esquema también se repite en los puestos de poder político, siendo nuevamente icónico el actual presidente de la República, quien estudió en el colegio Verbo Divino de la comuna de Las Condes (Figueroa, 2010).

El que uno de los lugares centrales de estas transformaciones esté en lo educacional implica que los grandes cambios repercuten directamente en ella. El desarrollo de los sistemas comerciales sustentados en la banca, el comercio y la producción manufacturera en talleres, estuvo aparejado con el nacimiento de la Universidad moderna, la emergencia del protestantismo, el desarrollo de un sistema de educación nacional universal (educación popular), el estatuto superior y diferenciado en el desarrollo de las profesiones libres versus otros oficios menores ${ }^{6}$, etc. Toda una articulación entre aspectos económicos (división del

${ }^{6}$ Adorno (Adorno, 1998) explica de este modo uno de los tabúes atribuibles a la docencia, una diferenciación clasista entre el profesor universitario y el de la escuela, hasta llegar a sus niveles iniciales, lo que tiene alcances económicos muy reales, como bien lo saben las educadoras de párvulo en Chile. 
trabajo), sociales (diferenciación de clases) y políticos (el voto universal en la mayor parte del mundo llegó en el siglo XX) sustentados en distintos tipos de educación.

Siempre que ocurren estas transformaciones, suceden de modo acelerado, disruptivo y violento: revoluciones, guerras, crisis políticas y económicas que llevan aparejadas desaparición de oficios y actividades tradicionales del anterior sistema productivo o pérdida de importancia y de valor económico, aunque no desaparezcan, entre otros impactos educativos. La frágil industria nacional desarrollada en torno a la CORFO desde los gobiernos radicales hasta Allende fue incapaz de sobrevivir al shock neoliberal, lo que incidió directamente en el sistema de escuelas técnicas de alto nivel que había construido el Estado de Chile en paralelo. El Departamento Universitario Obrero Campesino terminó convertido en una sigla, DUOC, al igual que el Instituto Nacional de Capacitación, INACAP ${ }^{7}$. Carcazas apenas después de una crisis sistémica, algo inherente al capitalismo.

\section{CRISIS SANITARIA Y APAGÓN EDUCATIVO GLOBAL}

A pesar de que la inmensa mayoría de las y los estudiantes, independiente de su país, zona geográfica, o desarrollo económico, estuvo sin clases durante gran parte del año 2020, nuevamente el impacto no fue igual entre las zonas más ricas del mundo y los países periféricos, entre los que se encuentran los Latinoamericanos. En este ámbito, el sistema educativo chileno mostró las mismas fracturas que otros países de nuestro subcontinente con desigualdades y carencias que en contextos de normalidad tienden a quedar invisibilizadas.

Estas transformaciones hoy aún tienen límites poco claros, pero la pandemia ha permitido vislumbrar ciertos aspectos que están cambiando. Por ejemplo, las modalidades de educación a distancia no habían logrado entrar hasta hoy, sin embargo, luego de las cuarentenas mundiales resulta evidente que no habrá retroceso en ellas $\mathrm{y}$, muy al contrario, implicarán transformaciones profundas en los modos de enseñar y aprender, especialmente en contextos de la educación de elite escolar y universitaria.

Luis Bonilla-Molina (Educativa, Alerta Educativa 293. Pandemia y Reingeniería Socioeducativa Global, 2020) llamó a esta situación Apagón Pedagógico Global (APG) ya en 2015 cuando junto a otros 236 educadores firmaron una carta dirigida a Irina Bokova, Directora General de la UNESCO, alertando sobre la ocurrencia de este fenómeno. Para el venezolano esto involucra varios elementos. Por una parte, el monopolio de la docencia virtual mediante las plataformas tecnológicas (Zoom, Jitsi, Meet, entre otras), los soportes informáticos (como Google, Wikipedia, etc.) y la intervención de la actividad docente despedagogizando la educación (fragmentándola en aspectos técnicos centrados en algunos de sus componentes como la didáctica, la planeación, el currículum, el gerenciamiento educativo, entre otros) y la desprofesionalización de la pedagogía, asociada a una desvalorización de la actividad y el rol de educador (ya que puede ser reemplazado por cualquier persona) y cierto desprecio al rol de la escuela y el aula, así como la diferenciación de saberes de primer y segundo orden (donde entran las humanidades y las artes). La realización en acto de este apagón, producto de la pandemia, fue el corolario de las

\footnotetext{
${ }^{7}$ Este último privatizado en Dictadura de un modo vergonzoso (Muñoz, 2018).
} 
contradicciones, pues estuvo directamente vinculada a la condición de clase. Sin embargo, a lo largo de Latinoamérica, el rol de las y los docentes pasó a ser incluso de contención emocional para estudiantes sin espacios adecuados o con graves problemas de hacinamiento.

Esto que parece una paradoja ocurre por dos aspectos. Mientras Chile junto a Uruguay son los países con mejor conectividad de Internet mediante dispositivos como computadores o notebook, esto no implica un computador por integrante familiar haciendo teletrabajo y otros haciendo educación a distancia. Tampoco se evidencia el problema de la velocidad de conexión, la que la mayoría de las veces resulta insuficiente para más de un computador y que no tiene disponibilidad técnica para aumentarse en muchas comunas ${ }^{8}$, independiente de la compañía. El problema ha sido subsanado en parte mediante la telefonía móvil, donde Latinoamérica tiene más de un $100 \%$ de cobertura de acuerdo a su población. A pesar de ello, como lo muestra el reportaje Un mundo sin escuelas (Huergo, 2020) de Damián Huergo, lo ocurrido durante 2020 no fue educación a distancia o tele-educación, sino una respuesta sobre la marcha con grandes problemas estructurales, escasa preparación previa de las y los docentes, incapacidad de apoyo desde los organismos centrales o directamente, desconocimiento de la realidad escolar. Indefectiblemente, el rol docente se reconfiguró en ámbitos sumamente diferenciados.

Para el caso de Chile (OPECH, 2020) diferentes estudios evidencian problemas en tres ámbitos fundamentales para las y los docentes: sobrecarga laboral, aspectos socio emocionales y apoyos insuficientes. Por mucho que nuestro sistema intenta diferenciarse del resto de Latinoamérica, la realidad es porfiadamente parecida. Aumento de las jornadas, indiferenciación entre los espacios y los tiempos del hogar y el trabajo, así como el desgaste emocional en un gremio altamente feminizado ${ }^{9}$, son la contraparte del alto compromiso que las y los docentes manifiestan al hablar de su trabajo y de sus estudiantes. Al igual que en el reportaje de Huergo, a lo largo y ancho de Latinoamérica, las y los docentes chilenos respondieron con creatividad, adaptabilidad técnica y un proceso de coeducación con sus estudiantes en plataformas tecnológicas que funcionaron como salas de clases virtuales (classroom), cuando las hubo. Mientras, la mayor parte del sistema público de educación y muchos subvencionados tuvieron que funcionar con guías ${ }^{10}$, algunas tutorías grabadas 0 docencia semanal, quincenal o dividida por minutos al interior de clases de una hora o de 45 minutos, las escuelas particulares fueron las primeras (y virtualmente únicas) en regresar a clases presenciales. En los colegios más elitistas del país la modalidad virtual contó con infraestructura, apoyos tecnológicos, enseñanza integral del currículum medible en evaluaciones estandarizadas, en conjunto con actividades que combinaban el uso de tecnología y el aprendizaje de contenidos.

\footnotetext{
${ }^{8}$ Por ejemplo, Santiago Centro, sede de 2 de los 3 poderes del estado y de gran parte de los Ministerios del país. 9 Lo que implica una sobrecarga adicional asociada a la distribución desigual de los horarios en asuntos familiares entre hombres y mujeres, pues estas últimas tienden a asumir casi en exclusiva el cuidado de los hijos e hijas (Humanas, 2020).

10 Tempranamente, en el mes de abril, Inés Dussel llamaba la atención sobre los principales desafíos y dificultades a los que se vería enfrentada la educación en contextos de emergencia sanitaria. La conferencia $L a$ Clase en pantuflas se convirtió en una especie de Best Seller educativo, siendo seguida en su momento por más de 19,000 docentes latinoamericanos y con más de 290,000 reproducciones hasta la actualidad (Dussel, 2020)
} 
Esto no resulta extraño si consideramos la pérdida de importancia de los Estados en temáticas educativas y el avance hacia un modelo centrado en el hogar, la familia y la gestión individual de lo educativo. Chile no sólo fue pionero en la aplicación de políticas neoliberales en educación, sino incluso más, un experimento radical que hasta el día de hoy tiene pocas comparaciones por su extensión temporal, geográfica y en los distintos niveles educativos, desde la educación universitaria hasta la enseñanza básica, y que de aprobarse las leyes de Sala Cuna Universal y de Equidad en Educación Parvularia del gobierno actual, extenderá el subsidio mediante voucher hasta los niveles iniciales ${ }^{11}$. Hasta el día de hoy y a pesar de que en temas educativos ya no nos rige la LOCE de Pinochet, la subsidiaridad y el principio de no discriminación entre la educación pública y privada, se sustentan en el derecho de los padres a elegir la educación para sus hijos/as, por sobre la obligación estatal de garantizar un acceso igualitario a la educación.

Esta exacerbación de paradojas en una de las sociedades con mayor ingreso per cápita de Latinoamérica y perteneciente a la OCDE explotó un par de meses antes de la llegada del virus al país. En lo que la prensa calificó como estallido social, otros revuelta o sublevación popular del 18 de octubre de 2019. Muchas de estas contradicciones en el diario vivir irrumpieron en el orden político e institucional (Espacio Autoeducativo Leftraru, 2020), obligando a está élite a un plebiscito para reemplazar la constitución de Pinochet.

Una tesis detrás de esta lectura de las paradojas (en términos sociales) es que son expresión de la emergencia de una ruptura, un quiebre en la ideología dominante, que va articulado con la puesta en evidencia de que el régimen de producción anterior está limitando la potencialidad productiva del nuevo que está naciendo. Por eso se reconfiguran sus instituciones, sus sistemas legales, sus filosofías, sus gnoseologías (la ciencia como tal tiene 400 años) y hasta las mismas actividades productivas.

Lo que hoy estamos viviendo en educación es igualmente paradójico que lo que está sucediendo con nuestras formas de organización política, social, productiva, cultural... militar. Una nueva formación social pugna por emerger mientras la institucionalidad, las leyes, las formas de trabajo y enseñanza resisten con todas sus fuerzas.

El divulgador de la filosofía Darío Sztajnszrajber ya se había referido a un aspecto de esta transformación como muerte del aula tradicional (Sztajnszrajber, 2017). En una conferencia dictada en Oaxaca, México ante docentes explicó esta idea sustentándola en una crítica al contenidismo que en su análisis era la característica del sistema de enseñanza tradicional. En palabras del argentino los contenidos están accesibles en la red, por lo que la vieja fórmula de la transmisión entendida como enseñanza, ya no tiene sentido. Esto no implica ni que la escuela desaparezca ni que el profesor o profesora dejen de ser importantes ni que el aula en tanto espacio deje de existir. Por el contrario, el aula se multiplica en una serie de instancias donde lo virtual coexiste con la ciudad y el espacio de la escuela se funde en las plataformas tecnológicas favoritas de los jóvenes como Instagran o más recientemente Tik Tok. Otro aspecto que releva Sztajnszrajber como un ámbito crítico para responder al desafío educativo actual es la separación que se produce entre investigación, docencia y

${ }^{11}$ Para un análisis por parte de una de las principales protagonistas de dichas leyes, revisar el Programa Alerta Educativa ${ }^{\circ} 308$ (Educativa, Alerta Educativa 308. Las Luchas de las/os Trabajadores de la Educación Parvularia..., 2020) 
divulgación, algo que considera una diferenciación falaz, pues un docente al sacar su clase del espacio de las cuatro paredes disuelve esta distancia entre las 3 actividades. Para el autor, vincular la clase a situaciones que ocurren en la cotidianidad urbana, usando el tiempo docente como un modo de incentivar la curiosidad y el proceso de investigación del propio estudiante, corroe esta separación, mostrando que sus hiatos no se corresponden con la realidad del enseñar - aprender.

Pero, uno de los aspectos donde se evidenciaron las mayores contradicciones durante el año 2020 tuvo que ver con la crisis de las formas evaluativas. En este campo las contradicciones, aporías, antinomias y dudas no debieron esperar a la finalización del año escolar, sino que emergieron en el corto plazo. mientras en varios países europeos se decidió por parte del Ministerio de Educación evitar la repitencia de la totalidad de estudiantes del sistema primario y secundario, en Chile el ministerio del ramo dio libertad a los liceos, escuelas y colegios para adoptar las medidas que ellos consideraran adecuadas. En sí mismo esto resultó contradictorio, teniendo en cuenta que la priorización curricular fue una decisión ministerial consultada en equipos técnicos seleccionados de modo unilateral por el ministerio aludido. Señalarle en forma explícita a las instituciones escolares los contenidos, habilidades y actitudes que debían quedar salvaguardados, mientras la decisión sobre la promoción o no de un/a niño/a o un/a joven quedaba al arbitrio de la propia escuela, muestra la poca sensibilidad y comprensión que tiene el sistema de la fragilidad en que se desenvuelven las comunidades educativas con docentes agobiados, estudiantes con dificultades de conexión, progenitores o tutores angustiados por la posibilidad de perder el trabajo. Las comunidades educativas no tuvieron un rol relevante ni fueron empoderadas para abordar un contexto de crisis con niveles de gobernanza que aportaran un mínimo de securitización respecto del proceso de enseñanza - aprendizaje.

\section{UNA CONCLUSIÓN ABIERTA}

Cuatro décadas de gerenciamiento educativo, privatización, desprofesionalización docente, criminalización del movimiento estudiantil, exclusión de las comunidades educativas, evaluación de alto impacto mediante instrumentos estandarizados, entre otros rasgos del neoliberalismo que se ha aplicado en la educación chilena, dejaron en evidencia la pérdida de un proyecto de educación nacional. Sin instituciones fuertes para apoyar la labor de la enseñanza, con profesores sin seguridad laboral y comunidades altamente dañadas, la realidad de la educación chilena en contextos de covid 19 muestra la fragilidad para afrontar el contexto de transformaciones productivas que la pandemia dejó en evidencia. La estrategia neoliberal no sólo ha fracasado respecto del pasado, sino que nos deja en un muy mal pie respecto del futuro.

Ad Portas de una discusión constitucional que podría marcar el futuro del país por las próximas décadas, el sentido común privatizador y las políticas neoliberales gozan de excelente salud y se encuentran relacionadas a niveles profundos con múltiples aspectos de la sociedad, la política, el derecho, la cultura, la educación, etc.

Al igual que en Estados Unidos antes de la abolición de la esclavitud moderna, todo el sistema político del sur estaba imbricado con formas esclavistas de trabajo, incluyendo las 
leyes que permitían funcionar al sistema y la legitimidad religiosa de la supremacía racial. En ese caso hizo falta una guerra civil para resolver un problema que afectaba al desarrollo económico de todo el país. La libertad formal que entregó Estados Unidos a la población negra después de la guerra de secesión no incluyó derechos políticos tan importantes como la participación electoral ni la inclusión educativa, que recién se vino a alcanzar en la década de los 60 del siglo siguiente gracias a las políticas de Kennedy. La paradoja de que pudiera ser presidente de este país un afroamericano fue seguida de la elección de un supremacista blanco como Trump. Nuestro presente tiene algo del dramatismo que dicho momento histórico representó para la sociedad norteamericana. Aunque las ideas que movían a los defensores de la libertad y el fin de la esclavitud terminaron por imponerse, el fracaso en el desarrollo de políticas reales y materiales que permitieran superar la condición social, económica y política de la esclavitud, terminaron siendo una espina clavada que impidió por más de un siglo (y luego de los eventos de Pittsburgh, parecieran existir hasta hoy) abordar adecuadamente las contradicciones que las transformaciones productivas le generan a las sociedades. Que en nuestro país la vía constitucional termine en éxitos formales y retrocesos materiales es alta. La única esperanza se encuentra en la capacidad de acción y movilización que ha tenido la sociedad chilena en un ciclo que se inició el año 2001 con el mochilazo, pero cuyas repercusiones siguen reverberando hasta hoy.

Al menos, el 2021 se abre con el manto de esperanza de casi dos décadas de lucha y la evidente incompetencia del poder constituido para administrar el nuevo contexto en que nos dejará la pandemia. La posibilidad de construir un bloque histórico con un gran proyecto de desarrollo nacional sustentado en la educación y el desarrollo científico, técnico y tecnológico, no podrán ser abordados por lo existente. Esta es una evidencia que la juventud chilena se ha ido haciendo al duro precio de los asesinatos represivos, el encarcelamiento como medida cautelar de miles de personas y 450 mutilados de uno o dos ojos. Como lo dijera Gustavo Gática, uno de ellos: "regalé mis ojos para que la gente despierte". El año que comienza nos mostrará si esas expectativas fueron sobredimensionadas o si por fin podremos recuperar la senda en temas educativos que nuestra sociedad construyó con grandes dificultades y luchas en sus dos primeros siglos de independencia.

\section{BIBLIOGRAFÍA}

Adorno, T. (1998). Tabúes sobre la profesión de enseñar. En T. Adorno, Educación para la Emancipación (págs. 65 - 78). Madrid: Ediciones Morata.

Beck, U. (2002). La sociedad del riesgo global. Madrid: Siglo XXI.

Beck, U. (2008). La sociedad del riesgo mundial. En busca de la seguridad perdida. Barcelona: Paidós.

Bonilla - Molina, L. (18 de marzo de 2020). En casa y sin tocar a los otros: coronavirus o reingeniería social a escala planetaria. Obtenido de Nodal: https://www.nodal.am/2020/03/en-casa-y-sin-tocar-a-los-otros-coronavirus-oreingenieria-social-a-escala-planetaria-por-luis-bonilla-molina/ 
Bourdieu, P. P. (1977). La Reproducción. Elementos para una teoría del sistema de enseñanza. Barcelona: Laia.

Dussel, I. (23 de Abril de 2020). La clase en pantuflas. Obtenido de Canal Youtube del ISEP: https://www.youtube.com/watch?v=6xKvCtBC3Vs

Educativa, A. (6 de Abril de 2020). Alerta Educativa 293. Pandemia y Reingeniería Socioeducativa Global. Obtenido de Canal de Youtube de Alerta Educativa: https://www.youtube.com/watch?v=Kr-znW8nLw0\&list=PLQymGC-

PIPTdo8ZeCKa49qzxVOEpLizeL\&index=4

Educativa, A. (31 de Agosto de 2020). Alerta Educativa 308. Las Luchas de las/os Trabajadores de la Educación Parvularia... Obtenido de Canal Youtube de Alerta Educativa: https://www.youtube.com/watch?v=amoza5B43dg\&feature=youtu.be

Espacio Autoeducativo Leftraru. (2020). Experiencia del Espacio Autoeducativo Leftraru (EAL) en el alzamiento social de Octubre. En V. Autores, 18 de octubre: primer borrador. Reflexiones desde abajo para pensar nuestro mañana (págs. 103 - 111). Santiago de Chile: Quimantú.

Expósito, M. (Dirección). (2004). Primero de mayo (La ciudad - fábrica) [Película].

Figueroa, J. y. (11 de noviembre de 2010). Verbo Divino: los secretos y el poder del colegio favorito de la élite. Obtenido de Ciperchile: https://www.ciperchile.cl/2010/11/11/verbo-divino-los-secretos-y-el-poder-delcolegio-favorito-de-la-elite/

FMI. (Abril de 2012). EL IMPACTO FINANCIERO DEL RIESGO DE LONGEVIDAD. Obtenido de IMF.ORG:

https://www.imf.org/external/spanish/pubs/ft/gfsr/2012/01/pdf/presss.pdf

Huergo, D. (23 de Diciembre de 2020). Un mundo sin escuelas. El ingenio de los maestros para seguir educando. Obtenido de Gatopardo: https://gatopardo.com/reportajes/sistema-educativo-en-america-latina-educar-entiempos-de-pandemia-covid-19/

Humanas. (22 de Mayo de 2020). Corresponsabilidad en cuarentena: Los hombres sobreestiman la cantidad de trabajo doméstico a su cargo. Obtenido de Humanas.cl: http://www.humanas.cl/corresponsabilidad-en-cuarentena-los-hombressobreestiman-la-cantidad-de-trabajo-domestico-a-su-cargo/

Marx, K. (1970). Manuscritos. Economía y filosofía. Madrid: Alianza.

Marx, K. y. (1974). La Ideología Alemana. Crítica de la novísima filosofía alemana en las personas de sus representantes Feuerbach, B. Bauer y Stirner y del socialismo alemán en las de sus diferentes profetas. Barcelona: Grijalbo.

Muñoz, A. A. (5 de Marzo de 2018). INACAP, institución creada para capacitar trabajadores, es desde 1990 una máquina de hacer dinero. Obtenido de piensachile.com: https://piensachile.com/2018/03/inacap-institucion-creada-capacitartrabajadores-desde-1990-una-maquina-dinero/ 
OPECH. (Septiembre de 2020). Principales resultados de encuestas sobre el trabajo del profesorado chileno en periodo de pandemia: condiciones de trabajo y malestar. Obtenido de OPECH: https://opech.cl/principales-resultados-de-encuestas-sobre-eltrabajo-del-profesorado-chileno-en-periodo-de-pandemia-condiciones-de-trabajo-ymalestar/

Patterson, O. (1991). La Libertad. La libertad en la construcción de la cultura occidental. Santiago de Chile: Ed. Andrés Bello.

Perasso, V. (12 de octubre de 2016). Qué es la cuarta revolución industrial (y por qué debería preocuparnos). Obtenido de BBC: https://www.bbc.com/mundo/noticias-37631834

Revista Internacional Marx Ahora. (2014). Formación Social. Revista Internacional Marx Ahora, $156 \quad-\quad 169 . \quad$ Obtenido de Inkrit.org: http://www.inkrit.org/neuinkrit/mediadaten/es/es_pdf/DHCM-MA37-Formacionsocial.pdf

Sepúlveda, N. y. (30 de Diciembre de 2020). Cecilia Morel viajó de vacaciones a Miami cuando los contagios por Covid ya mostraban un aumento. Obtenido de Ciperchile: https://www.ciperchile.cl/2020/12/30/cecilia-morel-viajo-de-vacaciones-a-miamicuando-los-contagios-por-covid-ya-mostraban-un-aumento /

Sztajnszrajber, D. (17 de Noviembre de 2017). El aula ha muerto: reflexiones filosóficas sobre la experiencia postaulica. Obtenido de Youtube: https://www.youtube.com/watch?v=mFr_hZp7G-M

Zizek, S. (2020). Pandemia. La covid 19 estremece al mundo. Barcelona: Anagrama. 